BÁRBARA JARRETA

\title{
RESISTÊNCIA ADESIVA DE RESINAS COM BAIXA CONTRAÇÃO DE POLIMERIZAÇÃO APÓS ENVELHECIMENTO DA INTERFACE ADESIVA.
}

Dissertação de mestrado à Faculdade de odontologia de Ribeirão Preto da Universidade de São Paulo, para obtenção do título de mestre em Ciências.

Programa: Odontopediatria.

Área de concentração: Odontopediatria.

Orientadora: Profa. Dra. Maria Cristina Borsatto

RIBEIRÃO PRETO 


\section{AUTORIZAÇÃo PARA RePRODUÇÃo}

Autorizo a reprodução e divulgação total ou parcial deste trabalho, por qualquer meio convencional ou eletrônico, para fins de estudo e pesquisa, desde que citada a fonte.

Ficha Catalográfica

Jarreta, Bárbara

Resistência adesiva de resinas com baixa contração de polimerização após envelhecimento da interface adesiva.

78 p.: Il; $30 \mathrm{~cm}$.

Dissertação de Mestrado, apresentada à Faculdade de Odontologia de Ribeirão Preto/USP. Área de concentração: Odontopediatria.

Orientadora: Borsatto, Maria Cristina

1. Adesão. 2. Resinas compostas 3. Degradação da interface. 


\section{FolHa de APROVAÇÃo}

Jarreta, B. Resistência adesiva de resinas com baixa contração de polimerização após envelhecimento da interface adesiva.

Dissertação de mestrado à Faculdade de odontologia de Ribeirão Preto da Universidade de São Paulo, para obtenção do título de mestre em Ciências.

Programa: Odontopediatria.

Área de concentração: Odontopediatria.

Aprovado em:

\section{BANCA EXAMINADORA}

$\operatorname{Prof}(a) \cdot \operatorname{Dr}(a)$ :

Julgamento: Assinatura:

Prof(a). $\operatorname{Dr}(a)$.:

Julgamento: Assinatura:

Prof(a). $\operatorname{Dr}(a)$.:

Julgamento: Assinatura:

Prof(a). Dr(a).:

Julgamento: Assinatura:

Prof(a). Dr(a).:

Julgamento: Assinatura: 



\section{BARBARA JARRETA}

\section{Dados Curriculares}

Nascimento

Filiação

2004-2008

2009-2011

2012-2012

2011-2013

2011-2014
02 de janeiro de 1987. Orlândia- SP

Milton Jarreta Júnior

Fátima Aparecida Peron Jarreta

Curso de Graduação em Odontologia.

Faculdade de Odontologia de Ribeirão Preto - UNAERP

Especialização em Odontopediatria

Associação Odontológica de Ribeirão Preto- AORP

Curso de Aperfeiçoamento em Atendimento Odontológico a Pacientes Especiais- FORP/USP

Curso de Aperfeiçoamento em Ortopedia Funcional dos Maxilares

Curso de Pós- Graduação em Odontopediatria, Nível de Mestrado

Faculdade de Odontologia de Ribeirão Preto da Universidade de São Paulo - Forp/ USP. 

"Pensamentos viram ações Ações viram hábitos Hábitos viram o carāter Eo carāter vira o seu destino". 

A DEUS por ter sempre proporcionado oportunidades abençoadas na minha vida, me iluminando para eu manter a perseverança nos meus objetivos e a calma necessária para o êxito.

Aos meus pais MILTON e FÁTIMA, ambos são responsáveis por cada sucesso obtido, pois o amor e a confiança de vocês me fortalecem todos os dias. Muito obrigado por tudo que fizeram e ainda fazem por mim. Vocês são e sempre serão meu maior porto seguro e simplesmente aqueles que mais amo.

Ao meu irmão NETO, como é bom ter você em minha vida, seu companheirismo e proteção moram em meu coração. 

Ao SANTO EXPEDITO, obrigado meu santo Expedito por sua poderosa interseç̧ão.

À minha avó ODETTE (in memorian) sempre muito presente em minha vida, quis o destino que ela partisse, mesmo não podendo estar mais ao meu lado eu sei que de onde ela está ela estará sempre me olhando, me guiando e comemorando mais uma vitória. Eu amo você!

À minha avó CYBELLE (in memoriam) uma pessoa que tinha um coração grandioso, quanta saudade!

AOs meus avôs ALEXANDRE e MILTON os avôs mais fofos que eu poderia ter. Vocês são demais.

À minha querida orientadora Profa. Dra. MARIA CRISTINA BORSATTO, a melhor orientadora que eu podia ter. Além de ser um exemplo de profissional, é um exemplo de uma grande pessoa com um coração sensacional. Cris, obrigado pelo acolhimento, pelas gargalhas deliciosas, pelos abraços calorosos, pela proteção, pela calma, muito obrigado por tudo. Você estará sempre no meu coração!

A Profa. Dra. ALEXANDRA MUSSOLINO DE QUEIROZ, Danda obrigado por sempre ter me ajudado, incentivado. O seu carinho e atenção foram muito importantes. você é muito especial.

Á CÍNTIA GUIMARÃES ALMEIDA, por todo companheirismo, paciência e dedicação. Cintia, obrigado por ter disponibilizado seu tempo para me ensinar. Sentirei falta das nossas conversas no laboratório. Você é muito especial. Conte sempre comigo! 
Ás minhas amigas e companheiras de mestrado DRIELY, SILVANA E LARISSA, sem a companhia de você o mestrado não teria sido tão especial, sentirei muita falta de vocês. Nossa amizade será eterna!

Ao DANIEL GALAFASSI, pela dedicação, disponibilidade e cuidado. Dani, obrigado por todo auxilio para conclusão deste trabalho.

À ALESSANDRA AFONSO CORREA por todo auxîlio, ensinamentos e atenção. Muito obrigado de coração!

Ao RODRIGO GALO pelo exemplo de competência e por toda ajuda para realizą̧ão deste trabalho.

À querida MARTA MARIA MARTINS GIAMATEI CONTENTE pelas conversas, pelas risadas e pelo carinho. Você é especial.

À minha prima SOFIA, muito obrigada por todos os favores, caronas. Sentirei falta das nossas conversas e confidências na estrada!

Ás minhas queridas amigas, companheiras de profissão e de consultório ANDREA e DANIELA, muito obrigado pelo carinho, ajuda e atenção.

"Não permita que a vida passe sem que as pessoas saibam o significado que elas têm para você" 
À FACULDADADE DE ODONTOLOGIA DE RIBEIRÃO PRETO DA UNIVERSIDADE DE SÃO PAULO, na pessoa do diretor Prof. Dr. VALDEMAR MALLET DA ROCHA BARROS a a Vice-Diretora Prof. Dra. LEA ASSED BEZERRA DA SILVA.

À Coordeną̧ão do Curso de Pós- Graduação em Odontopediatria da Faculdade de Odontologia de Ribeirão Preto da Universidade de São Paulo, na pessoa da Profa. Dra. LEA ASSED BEZERRA DA SILVA e do vice-Coordenador Prof. Dr. PAULO NELSON FILHO.

À Coordeną̧ão de Aperfeiçoamento de Pessoal de Nivel Superior (CAPES) pela bolsa de pesquisa concedida.

À Prof. Dra. RAQUEL ASSED BEZERRA SEGATO, muito obrigado por ter fornecido a resina Kalore utilizada neste estudo!

Aos docentes do departamento de Clinica Infantil e Social da Faculdade de Odontologia de Ribeirão Preto, São Paulo, Profas. Dras. Aldevina Campos de Freitas, Andiara de Rossi Daldegan, Kranya Victória Díaz Serrano, Léa Assed Bezerra da Silva, Sada Assed, Maria Bernadete Sasso Stuani, Mirian Aiko Nakane Matsumoto, Maria da Conceicão Pereira Saraiva e os Profs. Drs. Paulo Neson Filho, Adĩlson Tomasin, Făbio Romano, José Tarcisio Lima Ferreira, por todo conhecimento transmitido e divido conosco. Muito obrigado por fazerem parte da minha história!

À colega CAROLINA PAES TORRES MANTOVANI, pela amizade, carinho e paciência. Carol, obrigado pelos ensinamentos, você e sensacional!

Aos Colegas FRANCISCO WANDERLEY GARCIA DE PAULA E SILVA JACIARA MIRANDA GOMES DA SILVA obrigado por todo suporte. 
As amigas FERNANDA, KÉSSIA E MARÍLIA nossa amizade começou na especialização, se fortaleceu quando entrei no mestrado e comecei a dividir esta experiência com vocês. Muito obrigado por todas as palavras, carinho e disponibilidade, eu adoro vocês!

AOs amigos de MESTRADO E DOUTORADO do programa de Pós-Graduação em Odontopediatria pela experiência compartilhada nesses anos, todos são queridos.

À funcionária MICHELI CRISTINA LEITE ROVANHOLO, pela atenção, carinho e amizade. Mi você tem um coração enorme! Muito obrigado por tudo!

As funcionárias BENEDITA VIANNA e RENATA APARECIDA FERANDES RODRIGUES, pela convivência, carinho, cuidado. Sentirei falta dos abraços e conversas. Obrigado por tudo! Vocês são muito queridas!

Aos funcionărios FILOMENA E MATHEUS por toda atenção, paciência e amizade!

Aos funcionărios CARMO, KARINA, FÁTIMA RIZOLI, FÁTIMA DANIEL, MARCO, "SEU" ZEE E VERINHA pela paciência, ajuda e amizade, vocês são demais.

À ajudante dona MARIA, por todo carinho, atenção e alegria.

As funcionárias da seçãao de Pós- Graduação da faculdade de Odontologia de Ribeirão Preto da Universidade de São Paulo, ISABEL, REGIANE E MARY por toda ateņุão.

Aos técnicos EDSON e RICARDO do laboratório LIPEN, por toda disposição e auxillio para realização deste trabalho. 
Ao RODRIGO do Laboratório de Microscopia Eletrônica de Varredura (Departamento de Química - FFCLRP - USP) por todo suporte e competência.

A todos que torceram e contribuiram para realização deste sonho, meu eterno MUITO OBRIGADO!

"Enquanto estiver vivo, sinta-se vivo.

se sentir saudades do que fazia, volte a fazê-lo.

Não viva de fotografias amareladas...

Continue, quando todos esperam que desistas.

Não deixe que enferruje o ferro que existe em você.

Faça com que em vez de pena, tenham respeito por você.

Quando não conseguir correr através dos anos, trote.

Quando não conseguir trotar, caminhe.

Quando não conseguir caminhar, use uma bengala.

Mas nunca se detenha."

Madre Teresa de Calcutá 



\section{ResUmo}

\section{JARRETA, B. Resistência adesiva de resinas com baixa contração de} polimerização após envelhecimento da interface adesiva. [Mestrado]. Faculdade de Odontologia de Ribeirão Preto, Universidade de São Paulo; 2013.

Este trabalho avaliou in vitro a resistência à microtração de resinas compostas de baixa contração de polimerização em superfície dentinária após a degradação da interface adesiva. A amostra do experimento foi composta de 78 terceiros molares, sendo que 60 dentes foram divididos aleatoriamente em 6 grupos $(n=10)$ para 0 ensaio de microtração e 18 dentes adicionais (três dentes por grupo) foram utilizados para a análise da interface adesiva por meio da microscopia eletrônica de varredura (MEV). As variáveis de resposta quantitativas foram a resistência adesiva por meio do ensaio de microtração (Megapascal) e a classificação e cálculo dos valores percentuais dos tipos de fratura por meio de MEV. A análise estatística demonstrou que nos grupos NTC, o grupo Z250 apresentou diferença estatisticamente significante com os demais grupos $\mathrm{K}$ e P90, sendo estes semelhantes entre si. Após a realização da termociclagem observou diminuição nos valores de resistência nos grupos estudados, sendo que o grupo Z250 apresentou diferença estatisticamente significante em comparação ao grupo $\mathrm{K}$ e P90, que foram semelhantes entre si. A qualidade da interface adesiva por meio de MEV após o teste de microtração demonstrou que fraturas mistas foram prevalentes em todos os grupos avaliados. Em relação a interface adesiva, quando o sistema adesivo Clearfill SE Bond foi utilizado, pôde-se observar uma camada de adesivo espessa, camada híbrida e tags. No entanto, para o sistema adesivo P90, não foi possível observar camada híbrida, tags e foram observadas fendas interfaciais tanto às 24 horas como após envelhecimento.

Palavras-chave: Adesão; resinas compostas; degradação da interface. 



\section{ABSTRACT}

\section{JARRETA, B. Microtensile bond strength of polymerization o flow-shrinkage} composite resins after aging. [Mestrado]. Faculdade de Odontologia de Ribeirão Preto, Universidade de São Paulo; 2013.

This in vitro study evaluated the microtensile bond strength of polymerization of lowshrinkage composite resins in dentin surface after degradation of the adhesive interface. The sample of the study was composed by 78 third molars, 60 teeth were randomly divided into 6 groups $(n=10)$ for the microtensile testing and 18 additional teeth (three teeth per group) were used for the analysis of adhesive interface by means of scanning electron microscopy (SEM). The quantitative response variables were bond strengths to dentin through the microtensile test (Megapascal) and the classification and calculation of percentage values of theta peso fracture by SEM. Statistical analysis showed that the groups NTC, the Z250 group showed a statistically significant difference with others groups $\mathrm{K}$ and $\mathrm{P} 90$, which are similar to each other. After the performance of thermo cycling was observed decline in strength values of the studied groups, with the Z250 group showed a statistically significant difference when compared to the K group and P90, which were similar. The analysis showed the presence of mixed and adhesive fractures. Regarding the adhesive interface could be observed in P90 (NTC) and P90 (TC), presence cracks and gaps interfacial group. In the other groups was observed thick and dense layer Clearfill SE Bond and presence of tags into the tubules. Thus, it was concluded that the low polymerization shrinkage resins present lower average microtensile bond strength values both after 24 hours and after aging procedures of the adhesive interface. The quality of the adhesive interface by SEM after the microtensile test showed that mixed fractures were prevalent in groups Z250 (NTC), Z250 (TC), K (NTC), K (TC), P90 (NTC).And adhesive fracture was prevalent in the P90 group (CT).In relation the adhesive interface, when the adhesive system Clearfill SE Bond was used, it was noted a layer of thick adhesive, hybrid layer and tags. However, for the adhesive system P90, it was not possible to observe the hybrid layer, tags and interfacial cracks were observed both after 24 hours and after aging.

Keywords: Adhesion; resin composites; interface degradation 



\section{SUMÁRIO}

1. INTRODUÇÃO....................................................................

2. PROPOSIÇÃO ...................................................................... $\quad 29$

3. MATERIAL E MÉTODOS ................................................... 33

3.1 Delineamento Experimental ............................................. $\quad 35$

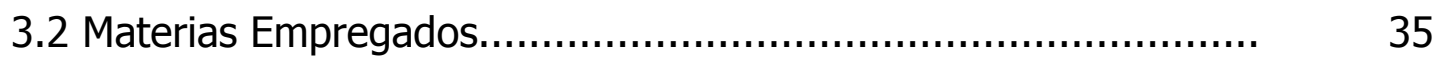

3.3 Seleção dos dentes............................................................

3.4 Preparo dos corpos de prova...............................................

3.5 Indução da lesão de cárie artificial...........................................

3.6 Procedimentos Restauradores............................................. $\quad 39$

3.7 Degradação da interface adesiva.............................................. 41

3.8 Ensaio de resistência de união à microtração............................. 43

3.9 Avaliação do padrão de fratura e da interface adesiva por meio de microscopia eletrônica de varredura (MEV)................................ 44

3.10 Análise dos dados.............................................................

4. RESULTADOS.....................................................................

4.1 Resultados do ensaio de resistência a microtração..................... $\quad 49$

4.2 Resultados do padrão de fratura........................................... 50

4.3 Resultados da análise morfológica.......................................... 53

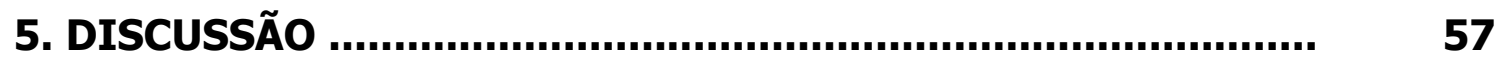

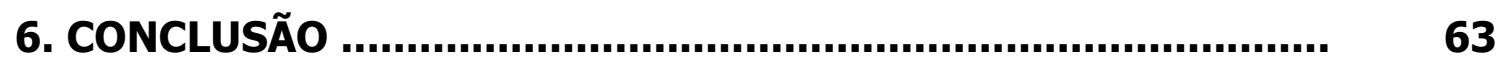

7. REFERÊNCIAS ................................................................ 67

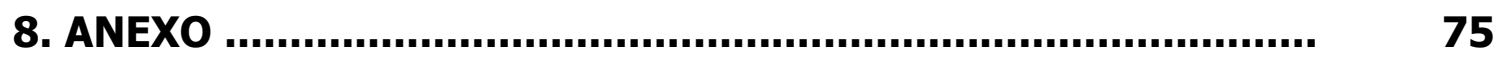



Introdução 



\section{INTRODUÇÃO}

Em todas as áreas da saúde, na qual se inclui a Odontologia, tem sido observada uma evolução significativa, evidenciada pelos seus avanços científicos e tecnológicos. Atualmente, a Odontologia Minimamente Invasiva, que visa a preservação do tecido dentário sadio, bem como a prevenção das doenças bucais, tem sido o conceito mais amplamente utilizado. Com isto, pôde ser constatado um aumento no número de restaurações em resina compostas principalmente em dentes posteriores, uma vez que não há necessidade de preparos cavitários extensos como realizados anteriormente quando os dentes eram restaurados com amálgama dental. No entanto, a longevidade das restaurações ainda é bastante afetada pelas consequências de sua contração de polimerização (Baracco et al., 2012) e que podem gerar microinfiltração, descoloração marginal, formação de fendas, deflexão do esmalte e sensibilidade pós operatória (Wernmann et al., 2005; Gonzaly-Lopes et al., 2007). O estresse gerado na interface adesiva logo após a fotoativação é um dos fatores responsáveis por estas falhas (Feilzer et al., 1993). Quanto maior a contração volumétrica mais rápida é a capacidade do material em alcançar propriedades elásticas e, assim, maior o estresse na interface adesiva (Feilzer et al., 1990).

Com a evolução dos materiais resinosos que buscam a melhora das propriedades físico-químicas nas restaurações a longo prazo, existe uma tendência a substituir a matriz convencional de Bis-GMA (bisfenol glicidil metacrilato) por uma matriz composta de resina com monômero silorano ou uma combinação de monômeros UDMA com DX-511 dimetacrilato, proporcionando assim, menor contração de polimerização (Boaro et al., 2010; Amaral et al., 2010) bem como melhor estabilidade hidrolítica do compósito (Eick et al., 2006; Wei et al., 2011).

Siloranos são monômeros a base de silício cuja molécula possui um núcleo de siloxano com quatro anéis anexos de oxirano que, durante a polimerização se abrem, unindo-se a outro monômero (Weinemann et al., 2005; Boaro et al., 2010). Em função deste mecanismo ocorre uma pequena redução da distância inicial entre 
monômeros, resultando no encolhimento volumétrico inferior a 1\%, gerando menor estresse sobre a interface adesiva (Baracco et al., 2012).

Recentemente, foram introduzidas no comércio resinas compostas com silorano na sua composição (Filtek P90 Silorano) e com a composição DX-511 dimetacrilato (Kalore).

A resina Filtek P90 Silorano possui sistema adesivo próprio, o Sistema Adesivo da Filtek P90. Este material apresenta algumas vantagens não somente em relação à contração volumétrica menor que $1 \%$ comparadas a resinas à base de metacrilato que normalmente contraem mais que $2 \%$, o profissional tem um tempo maior, aproximadamente de seis vezes para realizar a escultura (Weinmann et al., 2005; Iliie et al., 2006; Bouillaguet et al., 2006).

A resina Kalore contém na sua composição o monômero DX-511 que apresenta elevada massa molecular, proporcionando um composto com menor contração de polimerização. Além disto, este material é de fácil manipulação, apresenta excelente estética e alta durabilidade (Dopheide et al., 2010; Naoum et al., 2012).

A resina Z250 que foi utilizada como controle neste estudo, é uma resina microhíbrida, que apresenta na sua composição matriz orgânica Bis-GMA, que é uma estrutura química com alto peso molecular (Peutzfeldt,1997). Atualmente esta resina é muito utilizada pelos profissionais, pois possui excelente consistência, o que possibilita uma boa escultura durante a restauração.

Em relação aos sistemas adesivos, os sistemas adesivos autocondicionantes, apresentam vantagens em ralação aos demais sistemas adesivos, pois são aplicados em dentina seca e sua aplicação é simplificada, o que torna a técnica menos sensível quando comparada com sistemas que utilizam o condicionamento ácido prévio. 0 colapso da rede de colágeno ocasionado pela secagem é prevenido uma vez que a smear layer mantida é simultaneamente desmineralizada e polimerizada in situ. Além disso, a presença de smear layer torna a zona de colágeno exposto mais estável e menos sujeita a hidrólise (Nakabayashi \& Saimi., 1996). No entanto, a literatura é escassa em relação ao comportamento dos adesivos autocondicionantes associados aos materiais restauradores de silorano a longo prazo. 
Com o objetivo de simular as condições bucais e a avaliação das restaurações ao longo prazo, são realizadas in vitro as técnicas de envelhecimento (degradação), nas quais as mais empregadas usualmente são: a estocagem em água, realizada em diferentes períodos (Shono et al., 1999) e a termociclagem, que é uma técnica de envelhecimento indicada pela ISO, nos quais os corpos de prova devem ser submetidos a banhos de água, simulando as alterações térmicas ocorridas na cavidade bucal (Nakabayashi \& Pashley et al., 1996). Estudos recentes (do Amaral et al., 2008; do Amaral et al., 2010) mostram associações destes dois métodos para a avaliação da degradação da interface adesiva, uma vez que a termociclagem é o método mais utilizado para provocar o estresse da interface adesiva (Bedran de Castro., 2004), enquanto a armazenagem em água tem mostrado uma redução na resistência de união após curto período de estocagem, indicando que as ligações se degradam com o tempo (Carrilho et al., 2004).

Para mensurar a resistência à união entre o sistema adesivo e estrutura dentária podem ser utilizados diferentes ensaios mecânicos como: tração (Nakabayashi \& Saimi., 1996), microtração (Sano et al., 1994), microcisalhamento (Senawongse et al., 2004), cisalhamento (El-Kalla \& Garcia - Godoy., 1998). Dentre estes ensaios, o teste de microtração, apresenta algumas vantagens em relação aos demais uma vez que é necessário um menor número de dentes e a área de união é aproximadamente $1 \mathrm{~mm}^{2}$, o que faz com que os valores encontrados se tornem mais fidedignos, uma vez que a resistência é igual à força dividida pela área (Sano et al., 1994., Pashley et al., 1995).

Assim, em função da escassez de estudos que avaliem a resistência adesiva de resinas de baixa contração de polimerização utilizando o teste de microtração e da necessidade de um melhor entendimento do comportamento destas resinas a longo prazo em relação à adesão ao substrato dentinário, se faz necessário um incremento nas pesquisas com o objetivo de ampliar o conhecimento nesta área. 

Proposição 



\section{ProposiçÃo}

Considerando a evolução dos materiais restauradores estéticos, este estudo tem como objetivo:

- Avaliar in vitro a resistência à microtração de resinas compostas de baixa contração de polimerização associadas a adesivos autocondicionantes em superfície dentinária após a degradação da interface adesiva.

- Avaliar quantitativa e qualitativamente os padrões de fratura por meio de Microscopia Eletrônica de Varredura.

- Avaliar qualitativamente as interfaces adesivas por meio de Microscopia Eletrônica de Varredura. 

Material e Métodos 



\section{Material e Métodos}

\subsection{Delineamento Experimental}

Os fatores em estudo foram o sistema restaurador em 3 níveis: (Z250) Sistema Adesivo Clearfill SE Bond + Resina Filtek Z250; (K) Sistema Adesivo Clearfill SE Bond + Resina Kalore e (P90) Sistema Adesivo P90 + Resina Filtek P90; e a termociclagem em 2 níveis: (NTC) Sem ciclagem térmica (24 horas de armazenamento em água) e (TC) 12.000 ciclos térmicos (correspondente a 6 meses de degradação na cavidade bucal).

A amostra do experimento foi composta de 78 terceiros molares, sendo que 60 dentes foram divididos aleatoriamente em 6 grupos $(n=10)$ para o ensaio de microtração e 18 dentes adicionais (três dentes por grupo) foram utilizados para a análise da interface adesiva por meio da microscopia eletrônica de varredura (MEV). As variáveis de resposta quantitativas foram a resistência adesiva por meio do ensaio de microtração (Megapascal) e a classificação e cálculo dos valores percentuais dos tipos de fratura por meio de MEV. A variável de resposta qualitativa foi a análise descritiva da interface adesiva por meio de MEV.

\subsection{Materiais Empregados}

Para realização deste experimento foram empregados os seguintes produtos: os sistemas adesivos autocondicionantes Clearfil SE Bond (Kuraray CO. LTD., Umeda, Osaka, Japan) e P90 (3M/ESPE, Seefeld, Germany) e as resinas compostas Filtek Z250 (3M Dental Products,St Paul, MN, USA), Kalore (GC, Tokio, Japão) e Filtek P90 (3M/ESPE, St Paul, USA), demonstrados na Figura 1. As composições químicas e lotes estão descritos na Tabela 1. 
Tabela 1. Materiais empregados, composições químicas, fabricantes e lotes

\begin{tabular}{|c|c|c|c|}
\hline Materiais & Composição & Fabricante & Lote \\
\hline $\begin{array}{c}\text { Sistema } \\
\text { Adesivo P90 }\end{array}$ & $\begin{array}{l}\text { - Primer: Metacrilato fosfatado, } \\
\text { copolímero do ácido poliacrílico, } \\
\text { ácido carboxílico, BIS-GMA; } \\
\text { HEMA; água; etanol; } \\
\text { canforoquinona; partículas de } \\
\text { sílica tratadas com silano. } \\
\text { - Bond: canforoquinona, } \\
\text { dimetacrilato; hidrofóbicos, } \\
\text { metacrilatos hidrofóbicos } \\
\text { fosforilados, TEGMA. }\end{array}$ & 3M ESPE & N407720 \\
\hline $\begin{array}{c}\text { Clearfil SE } \\
\text { Bond }\end{array}$ & $\begin{array}{c}\text { - Primer: MDP, HEMA, água, } \\
\text { fotoiniciadores } \\
\text { - Bond: MDP, BisGMA, HEMA, } \\
\text { dimetacrilatos hidrofóbicos, } \\
\text { fotoiniciadores }\end{array}$ & Kururay & $01710^{a}$ \\
\hline Filtek ${ }^{\mathrm{TM}}$ P90 & $\begin{array}{c}\text { Matriz Orgânica: Silorano; } \\
\text { Conforoquinona; sais iodônicos. } \\
\text { Matriz Inorgânica: Partículas de } \\
\text { quartzo e fluoreto de ítio ( } 76 \% \\
\text { em peso) }\end{array}$ & 3M ESPE & N384451 \\
\hline Filtek ${ }^{\mathrm{TM}} \mathrm{Z250}$ & $\begin{array}{l}\text { Matriz orgânica: Bis-GMA, Bis- } \\
\text { EMA, TEGDMA, UDMA, } \\
\text { Canforoquinona } \\
\text { Matriz inorgânica: óxido de } \\
\text { alumínio, sílica e óxido de zircônia } \\
\text { (82\% em peso). }\end{array}$ & 3M ESPE & N431658 \\
\hline Kalore & $\begin{array}{c}\text { Matriz orgânica: UDMA, DX-511 } \\
\text { Matriz inorgânica: Carga pré- } \\
\text { polimerizada (com fluoreto de } \\
\text { lantanídeo), Vidro de fluoro- } \\
\text { alumino-silicato, Dióxido de silício, } \\
\text { fluoreto de lantanídeo. (82\% em } \\
\text { peso) }\end{array}$ & GC Co & 0907131 \\
\hline
\end{tabular}

BisGMA: Bisfenol A glicidil metacrilato; HEMA: 2- hidroxietil metacrilato; TEGDMA: trietilenoglicol dimetacrilato; MDP: 10-Metacriloiloxidecil dihidrogênio fosfato; BisEMA: Bisfenol A metacrilato etoxilado; UDMA: uretano dimetacrilato . 


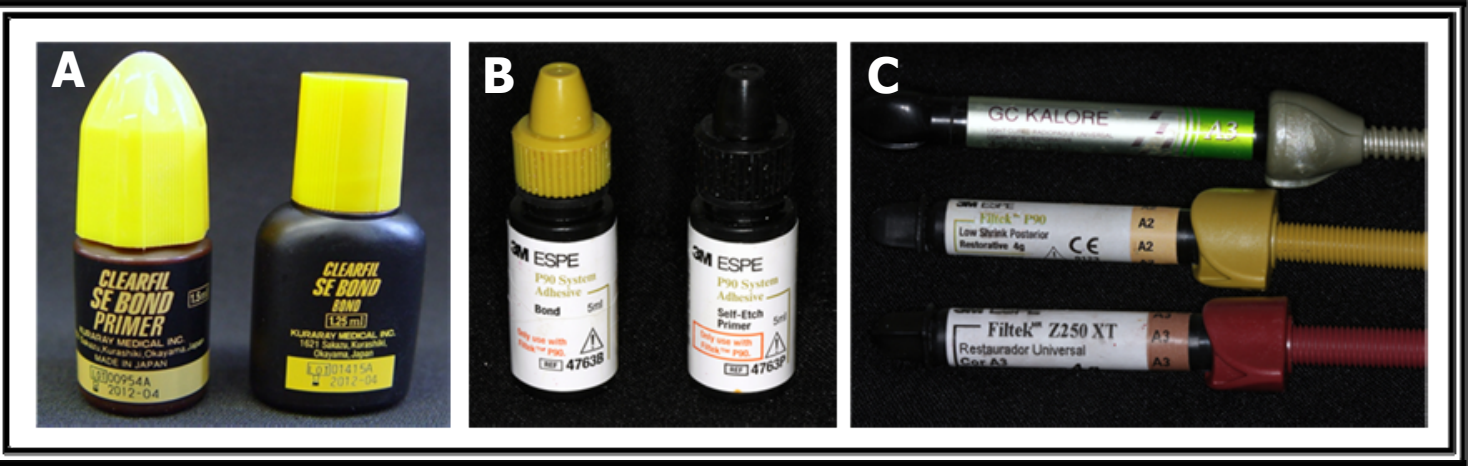

Figura 1. Materiais empregados no trabalho: (A) sistema adesivo autocondicionante de dois passos Clearfil SE Bond, (B) sistema adesivo autocondicionante de dois passos P90 (C) resinas compostas GC Kalore, Filtek P90 e Filtek Z250 XT.

\subsection{Seleção dos dentes}

Para a realização deste estudo foram utilizados 78 molares humanos recémextraídos, provenientes do Biobanco de Dentes Humanos da FORP-USP. Os dentes selecionados foram limpos com curetas e receberam profilaxia com escova de Robinson em baixa-rotação, com água e pedra pomes (Figura 2). Em seguida, os dentes foram lavados e armazenados em água destilada a $4^{\circ} \mathrm{C}$.

\subsection{Preparo dos corpos-de-prova}

As raízes dos dentes foram incluídas em resina acrílica utilizando matriz de silicone com dimensões $1,0 \times 1,5 \mathrm{~cm}$. As coroas foram seccionadas transversalmente removendo a superfície oclusal para exposição da superfície dentinária (Minitom, Struers A/S, Copenhagen, DK-2610, Denmark). Em seguida, a dentina exposta foi polida com lixas de carbeto de silício de granulações 360 e 600 montadas em politriz, refrigeradas com água (Figura 2). 

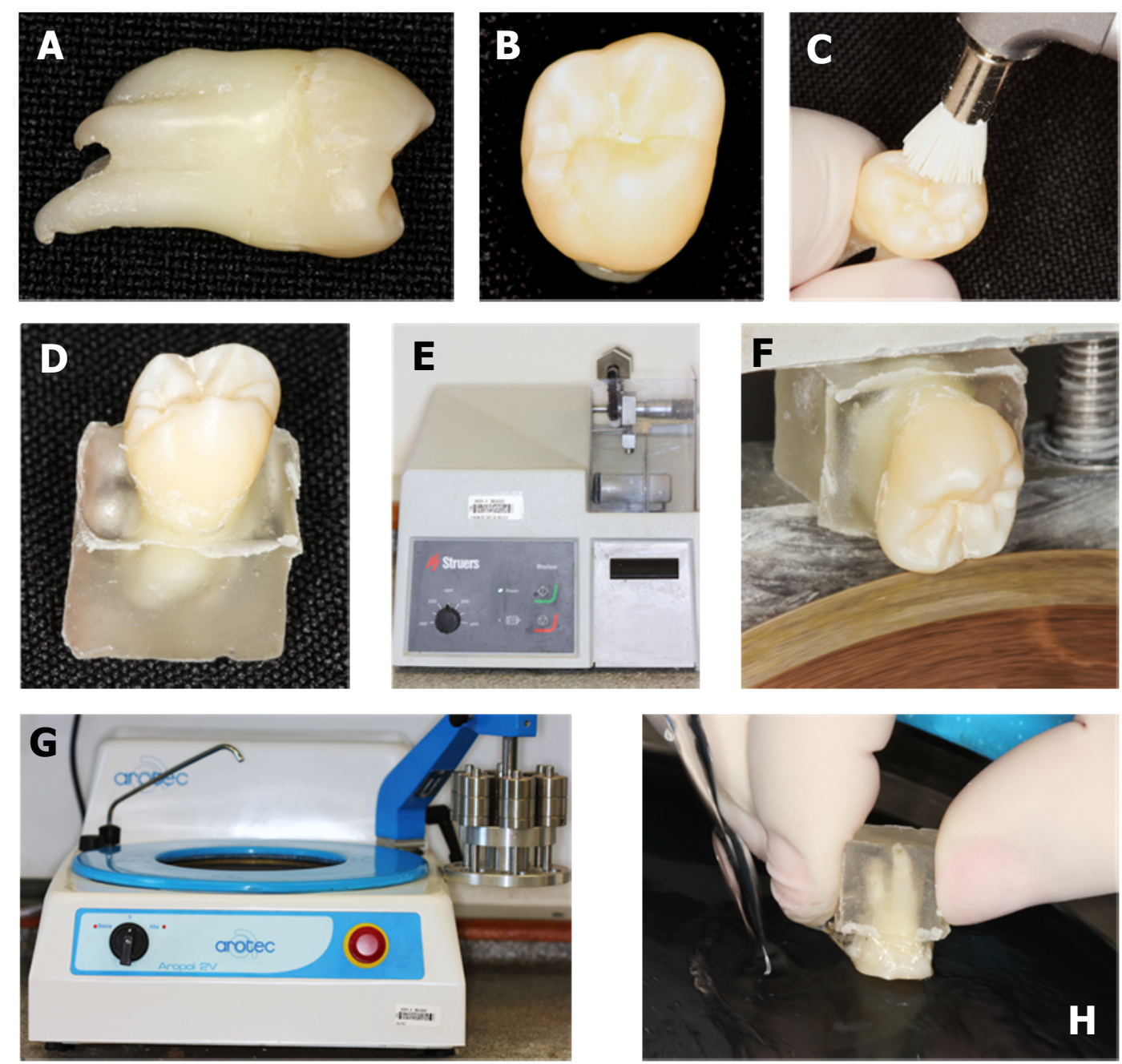

Figura 2. Imagens demonstrando o preparo do dente: (A) e (B) terceiro molar hígido; (C) profilaxia com pedra pomes e escova Robinson em baixa rotação; (D) raiz incluída em resina acrílica; (E) máquina de corte de precisão; (F) corte da superfície oclusal; (G) politriz utilizada para o desgaste; $(\mathrm{H})$ desgaste do dente com lixa e refrigeração com água.

\subsection{Indução de lesão de cárie artificial}

Os espécimes foram isolados com duas camadas de esmalte cosmético ácido resistente, deixando a superfície dentinária exposta e, em seguida, permaneceram imersos individualmente em $40 \mathrm{~mL}$ de solução desmineralizante $(2 \mathrm{mmol} / \mathrm{L}$ de cálcio, $2 \mathrm{mmol} / \mathrm{L}$ de fosfato e $75 \mathrm{~mol} / \mathrm{L}$ de acetato em pH 4,6) durante 12 dias consecutivos em estufa a $37^{\circ} \mathrm{C}$ (Estufa ECB - 1.3 Digital, Odontobrás Ind. E Com. De Equip. Méd. 
Odont. LTDA., Ribeirão Preto, SP, Brasil), sem necessidade de renovação da solução (Figura 3).

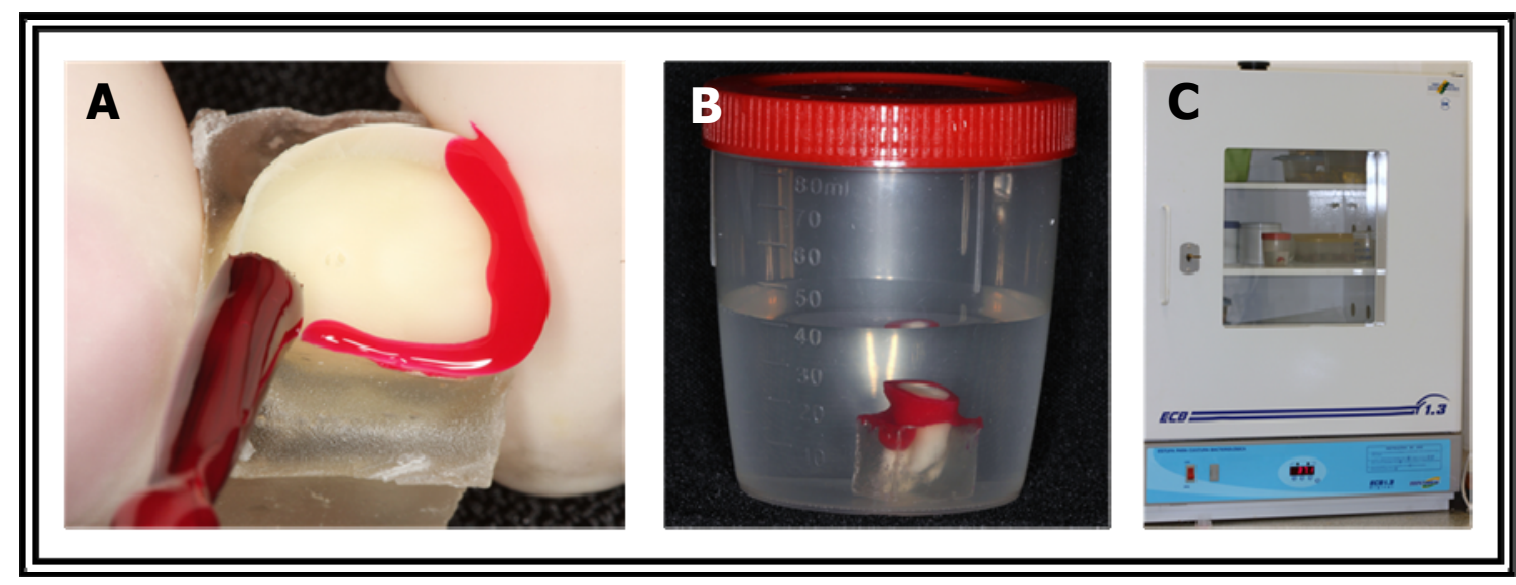

Figura 3. Preparo do espécime para indução de cárie artificial: $(A)$ isolamento do espécime com duas camadas consecutivas de esmalte cosmético expondo somente a superfície dentinária a ser desmineralizada; (B) imersão do espécime em $40 \mathrm{~mL}$ de solução desmineralizante; (C) permanência dos espécimes em estufa a $37^{\circ} \mathrm{C}$ por 12 dias.

\subsection{Procedimentos Restauradores}

Após a indução de lesão de cárie artificial, os espécimes foram preparados com broca de aço esférica no 4, montada em contra-ângulo em baixa rotação (KaVo do Brasil Ind. Com. Ltda, Joinvile, SC, Brasil), sendo substituída a cada cinco preparos. Após os preparos utilizou-se uma sonda exploradora para averiguar se o tecido dentinário apresentava-se resistente. Os preparos simularam os procedimentos realizados em clínica, procurando a máxima preservação de tecido sadio e com o próprio operador manuseando a turbina de baixa rotação. Sobre a dentina preparada foram realizadas as restaurações de acordo com o sistema restaurador a ser avaliado.

No grupo Z250 foi aplicado o sistema adesivo autocondicionante Clearfil SE Bond (Kuraray CO. LTD., Umeda, Osaka, Japão) de acordo com as instruções do fabricante. Primeiro aplicou-se o primer, friccionando-se a ponta aplicadora descartável na superfície dentinária durante 20 segundos, seguido de um leve jato 
de ar. A seguir, foi aplicado o adesivo com ponta aplicadora seguido de um leve jato de ar e fotoativado durante 10 segundos. Os espécimes foram então restaurados com a resina composta Filtek Z250 (3M Dental Products, St Paul, MN, USA), sendo confeccionado um platô de resina com $4 \mathrm{~mm}$ de altura, aplicado em 4 incrementos de $1 \mathrm{~mm}$ cada, fotoativados com fonte de luz halógena (Ultralux, Dabi Atlante SA Ind. Médico Odontológicas, Ribeirão Preto, SP, Brasil) durante 20 segundos após cada inserção de modo contínuo, com intensidade de $615 \mathrm{~mW} / \mathrm{cm}^{2}$, aferida por meio de radiômetro (RD-7, Ecel Ind. e Com. Ltda, Ribeirão Preto, SP, Brasil) a cada dez espécimes restaurados.

O grupo K também recebeu o sistema adesivo Clearfil SE Bond (Kuraray CO. LTD., Umeda, Osaka, Japão) e para a confecção da restauração foi utilizada a resina composta Kalore (GC, Tokio, Japão), que foi realizada como descrito no grupo Z250.

No grupo P90, o sistema adesivo utilizado foi o P90 (3M/ESPE AG, Seefeld, Germany) de acordo com as instruções do fabricante. O primer foi aplicado com auxílio de uma ponta aplicadora descartável, friccionando-o na superfície dentinária durante 15 segundos, seguida de aplicação de suave jato de ar (5 segundos) e fotoativação durante 10 segundos com fonte de luz halógena de intensidade de 615 $\mathrm{mW} / \mathrm{cm}^{2}$ de potência, aferida com um radiômetro a cada dez espécimes fotoativados. Em seguida foi aplicado o adesivo com ponta aplicadora descartável, uniformizando-se a camada com a aplicação de suave jato de ar durante 5 segundos e fotoativação por 10 segundos. A restauração do espécime foi então realizada com a resina composta Filtek P90 (3M/ESPE, St Paul, MN, USA) sendo confeccionado um platô de resina com $4 \mathrm{~mm}$ de altura, aplicado em 4 incrementos de $1 \mathrm{~mm}$ cada que foram individualmente fotoativados durante 40 segundos (Ultralux, Dabi Atlante SA Ind. Médico Odontológicas, Ribeirão Preto, SP, Brasil), de acordo com instruções do fabricante. Os procedimentos restauradores estão demonstrados na Figura 4. 


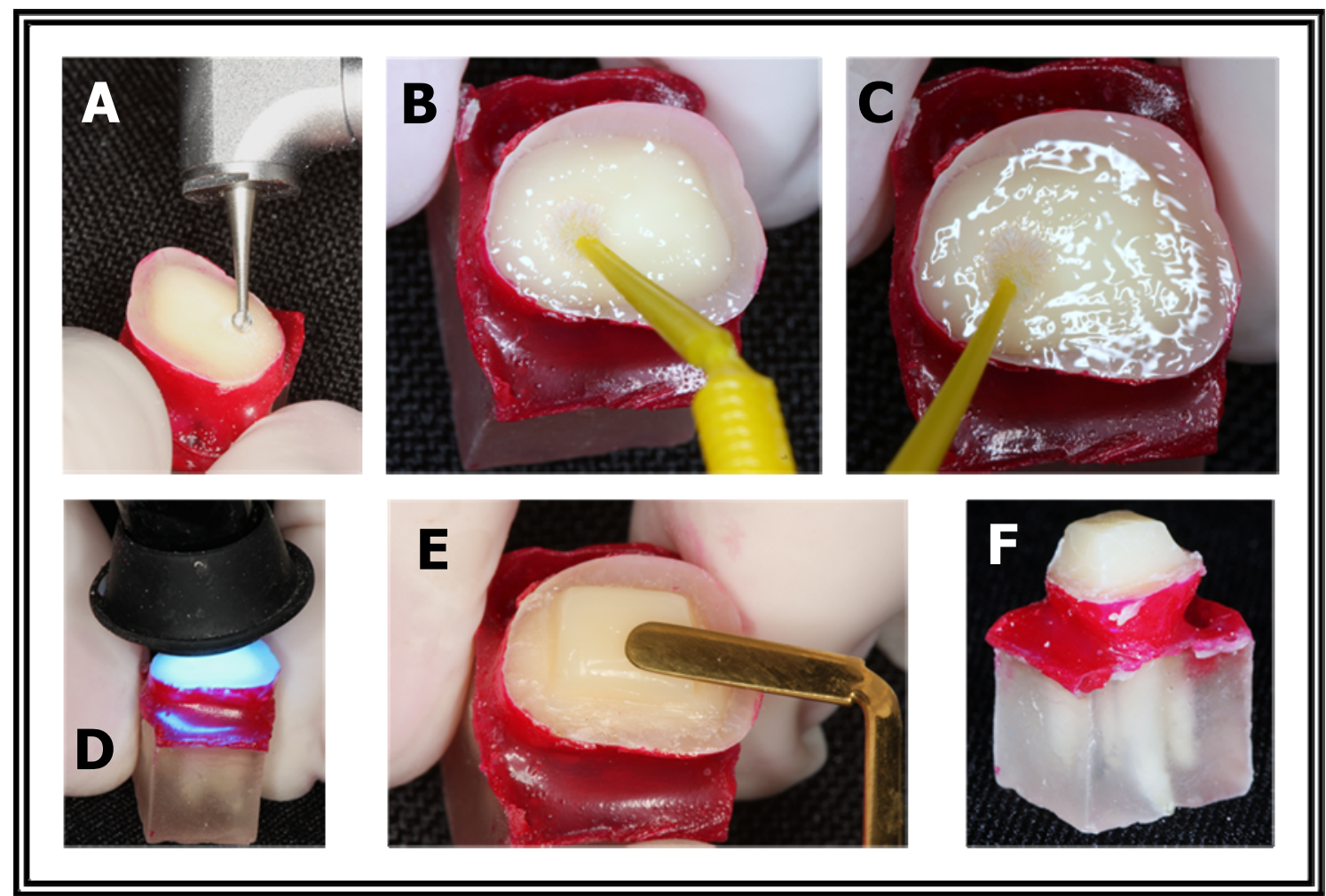

Figura 4. Procedimentos restauradores: $(A)$ preparo do espécime com broca de aço em baixa rotação; $(B, C)$ aplicação dos sistemas adesivos de acordo com as instruções dos fabricantes; (D) fotoativação do sistema adesivo; (E) confecção dos platôs de resina em incrementos e $(F)$ platô de aproximadamente $4 \mathrm{~mm}$ de altura.

\subsection{Degradação da interface adesiva}

Os espécimes restaurados foram mantidos em água destilada a $37^{\circ} \mathrm{C}$ durante 24 horas e divididos em 6 subgrupos $(n=10)$ de acordo com a simulação da degradação da interface adesiva, como descrito na Tabela 2. Três subgrupos foram testados imediatamente após as 24 horas (Sem termociclagem - NTC) e três subgrupos foram submetidos à ciclagem térmica (TC). 
Tabela 2. Blocos experimentais

\begin{tabular}{ccc}
\hline & \multicolumn{2}{c}{ Envelhecimento } \\
\cline { 2 - 3 } Materiais & Sem termociclagem (NTC & $\mathbf{1 2 . 0 0 0}$ ciclos térmicos (TC \\
$\mathbf{N}=\mathbf{1 0}$ & $\mathbf{N}=\mathbf{1 0}$ \\
$\mathbf{Z} \mathbf{2 5 0}$ & Z 250 NTC & Z 250 TC \\
K & K NTC & K TC \\
P 90 & P 90 NTC & P 90 TC \\
\hline
\end{tabular}

Os ciclos térmicos foram realizados em máquina de termociclagem, demonstrada na Figura 5 (MSCT-3, São Carlos, SP, Brasil).

Cada ciclo consistiu de imersão em água em duas temperaturas distintas $\left(5^{\circ} \mathrm{C}\right.$ e $\left.55^{\circ} \mathrm{C}\right)$ com tempo de permanência de 30 segundos em cada banho e tempo de transferência de 7 segundos. Foram realizados 12.000 ciclos térmicos no total.

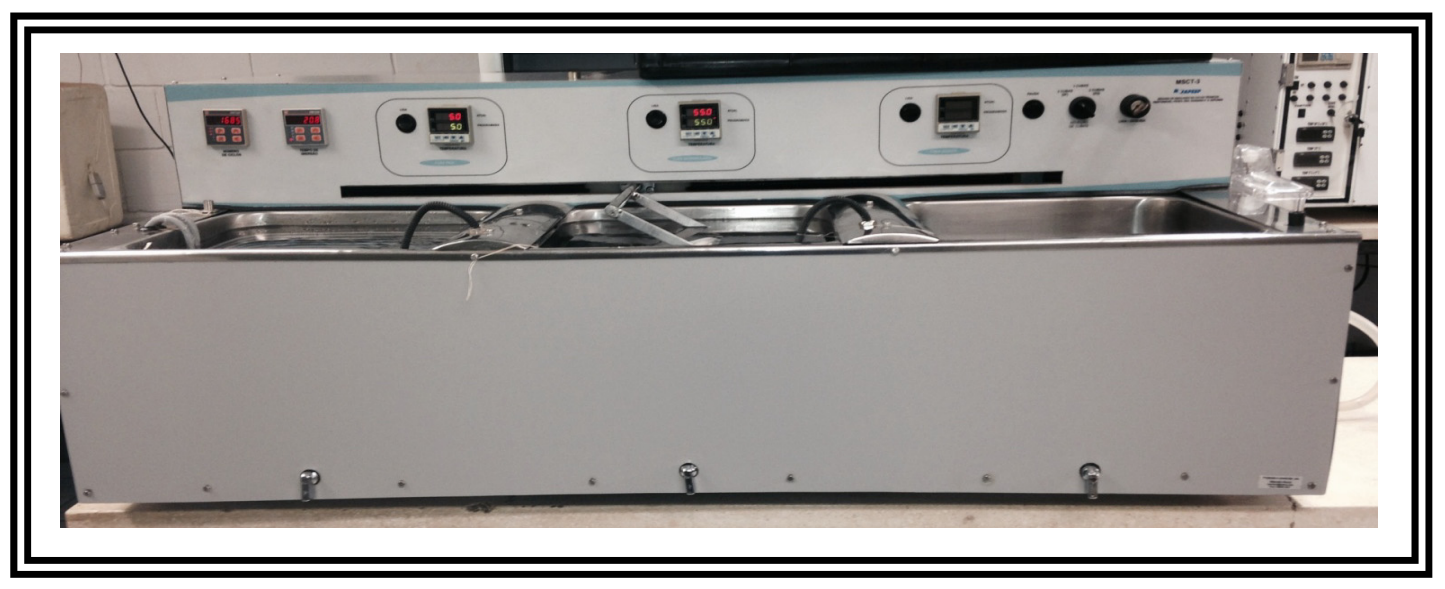

Figura 5. Máquina de termociclagem 


\subsection{Ensaio de resistência de união à microtração}

Após a ciclagem térmica, os espécimes foram imersos em água destilada, e mantidos em estufa a $37^{\circ} \mathrm{C}$ durante 24 horas. A seguir, os espécimes foram cortados para a obtenção de palitos com área de secção transversal de aproximadamente 1 $\mathrm{mm}^{2}$. A medição da área transversal de cada palito foi realizada com um paquímetro digital (Mitutoyo, Tokyo, Japan) e, em seguida, os espécimes foram fixados pelas suas extremidades à máquina de ensaio universal (EMIC Equipamentos e Sistemas de Ensaio Ltda, São José dos Pinhais, PR, Brasil) por meio de um adesivo à base de cianocrilato (Super Bonder Gel, Henkel Ltda., São Paulo, SP, Brasil). O teste foi realizado a uma velocidade de $0,5 \mathrm{~mm} / \mathrm{min}$, utilizando uma célula de carga de $50 \mathrm{Kgf}$. Os valores finais de resistência adesiva foram expressos em MPa. O preparo para o ensaio de microtração está demonstrado na Figura 6.

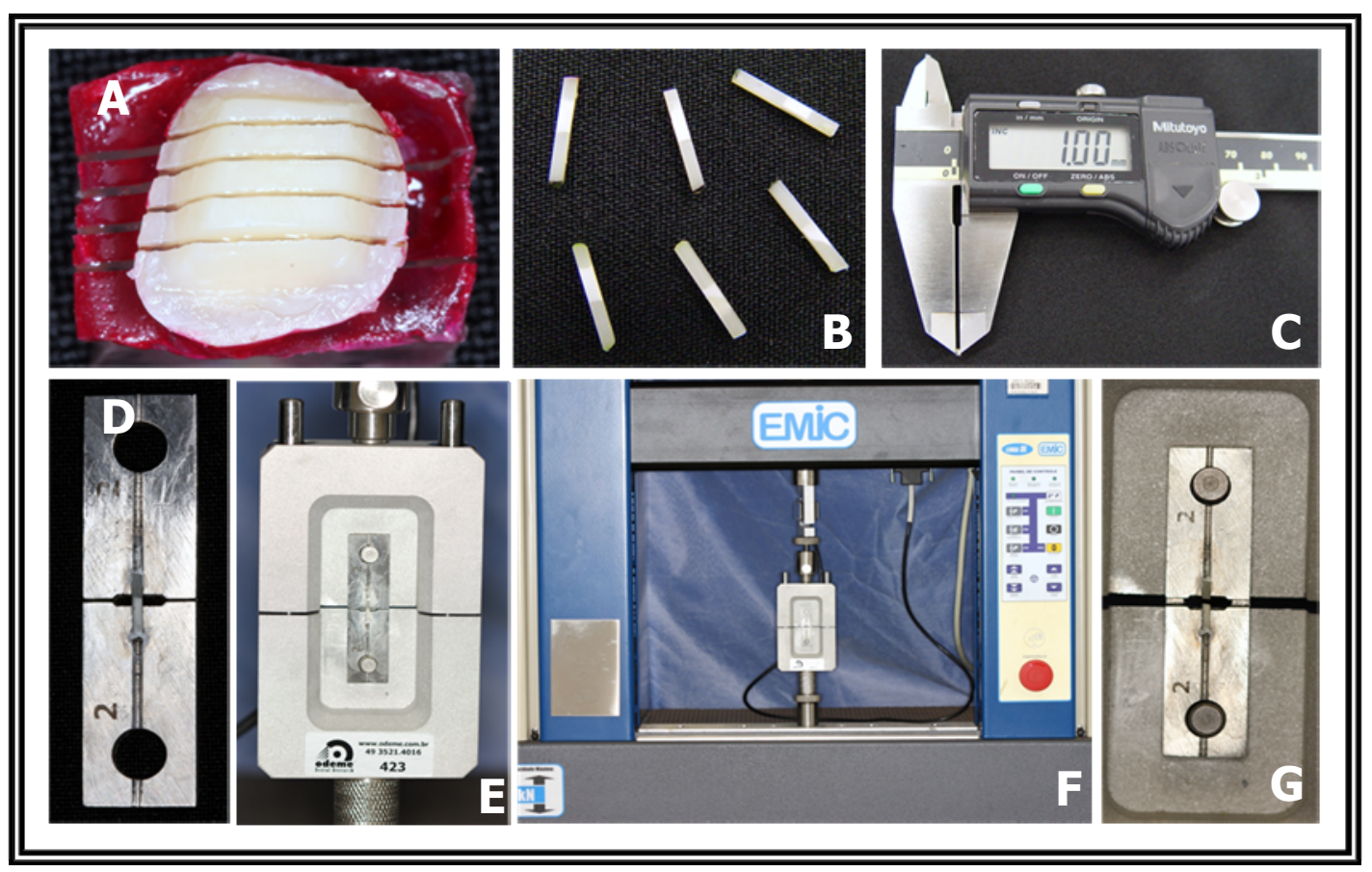

Figura 6. Ensaio de resistência à microtração: $(A)$ Corte seriado do espécime para produção dos palitos; (B) palitos apresentando aproximadamente $1 \mathrm{~mm}^{2}$ de área transversal; (C) medição realizada com paquímetro digital; (D, E, F) corpo de prova colado na garra para microtração e posicionado no dispositivo fixado na máquina de ensaio universal para a realização do teste $(\mathrm{G})$ corpo de prova fraturado após o teste. 


\subsection{Avaliação do padrão de fratura e da interface adesiva por meio de microscopia eletrônica de varredura (MEV)}

Para avaliar os padrões de fratura após o teste de resistência adesiva, todos os fragmentos foram observados em microscopia eletrônica de varredura (EVO Carl Zeiss, Oberkochen, Baden-Wurttemberg, Germany). Os tipos de fratura foram classificados em fratura adesiva (rompimento na interface dentina/adesivo); fratura coesiva em dentina (rompimento da estrutura dentinária); fratura coesiva em resina (rompimento da resina) e fratura mista (presença de fratura em dentina e/ou resina em um mesmo corpo de prova).

Para a análise da camada híbrida foram utilizados 18 corpos de prova, divididos aleatoriamente nos seis grupos experimentais $(n=3)$, que após receberem os procedimentos restauradores e a termociclagem, foram seccionados longitudinalmente em máquina de corte (Minitom, Struers, Dinamarca) obtendo-se fragmentos de aproximadamente $2 \mathrm{~mm}$ de espessura. Os fragmentos foram polidos em politriz (Acopol 2V, Arotec S/A Indústria e Comércio, Cotia, SP, Brasil) com lixas de carbeto de silício com granulação ascendente de 400, 600 e 1200, e com discos de feltro e alumina $3 \mu \mathrm{m}$. Todos os espécimes avaliados em MEV foram tratados de acordo com o seguinte protocolo: imersão em EDTA trissódico (Biodinâmica Quím. E Farm. LTDA, Ibiporã, PR, Brasil) durante 5 minutos, lavados, imersos em água destilada e mantidos em um aparelho de ultrassom (Ultrasonic Cleaner T-1449D, Odontobrás, Ribeirão Preto, SP, Brasil) durante 10 minutos, para a remoção de possíveis resíduos. A seguir, os espécimes foram secos com papel absorvente e desidratados com imersão em graus ascendentes de etanol (Merck KGaA, Darmstadt, Germany): 25\% (20 min), 50\% (20 min), 75\% (20 min), 95\% (30 min) e 100\% (60 min), seguido da imersão em HMDS (Hexamethyldisiloxane - SIGMA-ALDRICH, Co., St. Louis, USA) durante 10 minutos para a secagem química com o objetivo de minimizar as alterações da superfície examinadora, favorecendo a disposição subseqüente da camada de ouro, a fim de deixar mais nítido o campo a ser visto.

Após todos os tratamentos, as amostras foram fixadas em stubs com o auxílio de uma fita adesiva dupla-face de carbono e a cobertura de ouro foi realizada 
em aparelho de metalização a vácuo (SDC 050, Bal-Tec AG, Balzers, Liechtenstein). Os stubs foram levados ao Microscópio Eletrônico de Varredura (EVO Carl Zeiss, Oberkochen, Baden-Wurttemberg, Germany) do Departamento de Química da Faculdade de Filosofia, Ciências e Letras de Ribeirão Preto da Universidade de São Paulo para a obtenção das imagens.

\subsection{Análise dos dados}

Os dados foram avaliados pelos testes de normalidade Kolmogorov-Smirnov e Shapiro-Wilk, não apresentando distribuição homogênea. Portanto, o teste selecionado para amostra foi utilizado o teste de Kruskal-Wallis ao nível de significância de $5 \%$ e testes paramétrio complementar de Mann-Whitney.

A análise das eletromicrografias das interfaces adesivas obtidas por meio de MEV foi descritiva, e as imagens dos espécimes fraturados no ensaio de microtração foram classificadas de acordo com o tipo de fratura em fratura adesiva (rompimento na interface dentina/adesivo); fratura coesiva em dentina (rompimento da estrutura dentinária); fratura coesiva em resina (rompimento da resina) e fratura mista (presença de fratura em dentina e/ou resina em um mesmo corpo de prova). 

Resultados 



\section{Resultados}

\subsection{Resultados do ensaio de resistência adesiva a microtração}

Os valores médios e desvio padrão de microtração dos diferentes grupos estão demonstrados na tabela 3.

Tabela 3. Valores de resistência adesiva (MPa)

\begin{tabular}{lcc}
\hline \multirow{2}{*}{ Grupos } & \multicolumn{2}{c}{ Envelhecimento } \\
\cline { 2 - 3 } & \multicolumn{1}{c}{$\mathbf{( \text { NTC) }}$} & $\begin{array}{c}\mathbf{1 2 . 0 0 0} \\
\text { ciclos térmicos(TC) }\end{array}$ \\
$\mathbf{2 2 5 0}$ & $25.29(10,91)^{\mathrm{Aa}}$ & $13.00(10,76)^{\mathrm{Aa}}$ \\
$\mathbf{K}$ & $9,69(11,63)^{\mathrm{Ba}}$ & $4.30(6,40)^{\mathrm{Ba}}$ \\
$\mathbf{P 9 0}$ & $9,81(8,49)^{\mathrm{Ba}}$ & $0(0)^{\mathrm{Bb}}$ \\
\hline
\end{tabular}

Letras minúsculas indicam análise por colunas e maiúsculas por linhas

Ao analisar os grupos em NTC (sem termociclagem térmica), o grupo Z250 apresentou diferença estatística significante $(p=0,015)$ com os demais grupos $\mathrm{K}$ e P90, sendo que estes foram semelhantes entre si. Após a realização da termociclagem pode-se observar diminuição nos valores de resistência nos grupos estudados, sendo que o grupo Z250 apresentou diferença estatística significante ( $p=0,001$ ) em comparação ao grupo P90 e K, que foram semelhantes entre si.

Ao se comparar os grupos que foram testados após 24 horas de armazenamento com os que foram termociclados, houve diferença significativa apenas para o grupo da $P 90(p=0,002)$. 


\subsection{Resultados do padrão de fratura}

Tabela 4. Valores percentuais dos padrões de fratura.

\begin{tabular}{ccccc}
\hline & \multicolumn{4}{c}{ TIPOS DE FRATURA } \\
\cline { 2 - 5 } MATERIAIS & MISTA & ADESIVA & $\begin{array}{c}\text { COESIVA EM } \\
\text { DENTINA }\end{array}$ & $\begin{array}{c}\text { COESIVA EM } \\
\text { RESINA }\end{array}$ \\
\hline Z250(NTC) & $65 \%$ & $26 \%$ & - & $9 \%$ \\
Z250(TC) & $69 \%$ & $21 \%$ & $10 \%$ & - \\
Kalore(NTC) & $55 \%$ & $33 \%$ & $12 \%$ & - \\
& & & & - \\
Kalore(TC) & $51 \%$ & $41 \%$ & $8 \%$ & - \\
& & & & - \\
P90(NTC) & $66 \%$ & $16 \%$ & $15 \%$ & \\
P90(TC) & $25 \%$ & $62 \%$ & $13 \%$ & \\
& & & & \\
\hline
\end{tabular}

Os padrões de fraturas foram analisados após o teste de microtração e verificou-se predomínio de fraturas mistas para os grupos Z250(NTC), Z250(TC), $\mathrm{K}(\mathrm{NTC}), \mathrm{K}(\mathrm{TC}), \mathrm{P} 90(\mathrm{NTC})$ e predomíno de fratura adesiva para o grupo $\mathrm{P} 90(\mathrm{TC})$. 


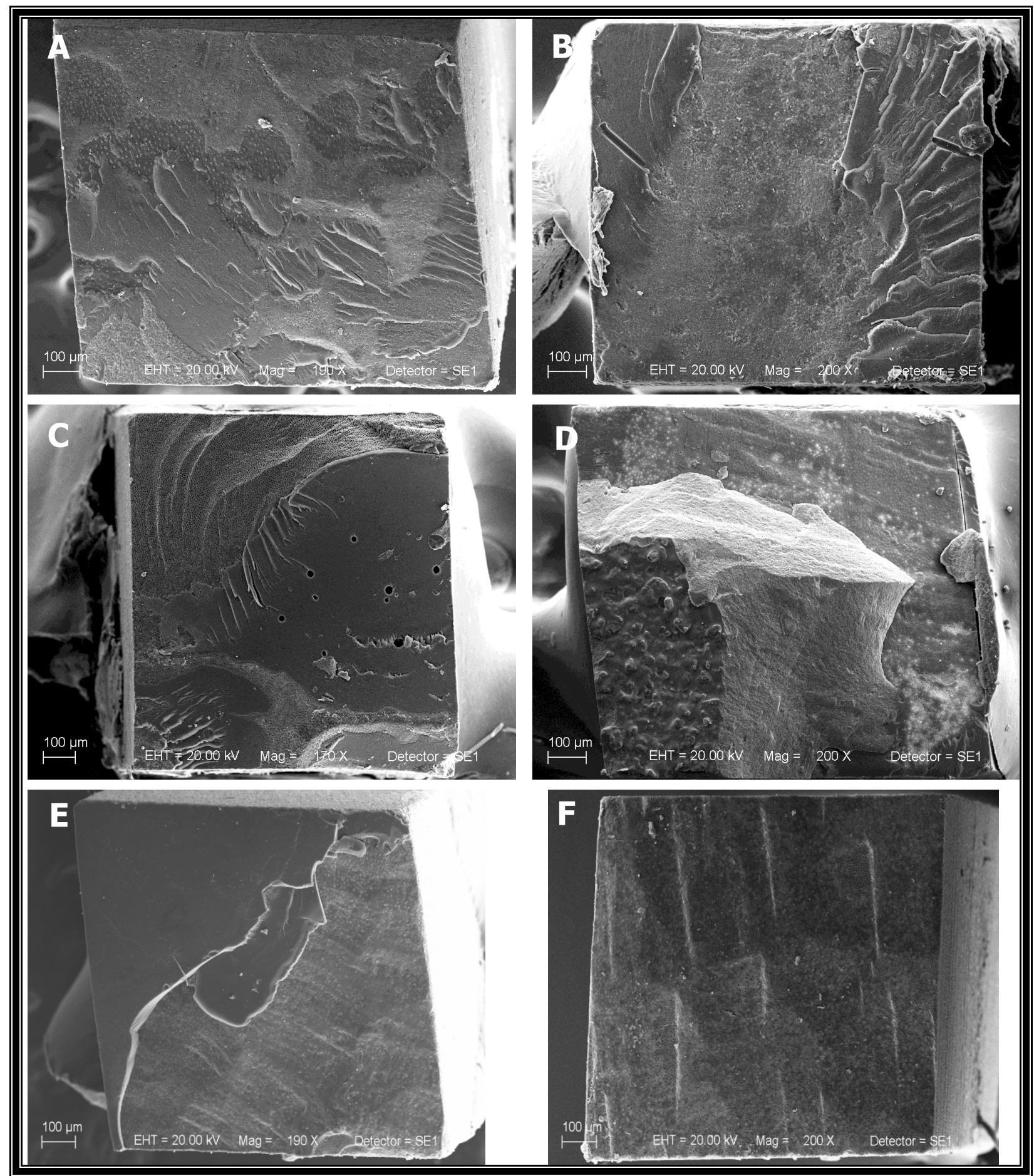

Figura 7. Imagens representativas das fraturas de maior ocorrência para os diferentes grupos estudados, avaliadas por Microscopia Eletrônica de Varredura (200X): (A) fratura mista do grupo Z250(NTC); (B) fratura mista do grupo Z250(TC); (C) fratura mista do grupo K(NTC); (D) fratura mista do grupo K(TC); (E) fratura mista do grupo P90 (NTC); (F) fratura adesiva do grupo P90(TC). 



\subsection{Resultados da análise morfológica}

Á análise morfológica da interface adesiva dos grupos demonstrou que, quando o sistema adesivo Clearfill SE Bond foi utilizado em associação à resina Z250(NTC), foi observado uma camada de adesivo espessa com formação de tags. Após o envelhecimento, o padrão mantém o mesmo, sendo observado a presença de gap na interface.

Resultados semelhantes foram encontrados no grupo $\mathrm{K}(\mathrm{NTC})$, no qual o sistema adesivo Clearfill SE Bond associado a resina composta Kalore, demonstrou uma camada de adesivo espessa e alguns tags. E após envelhecimento, K (TC), seguiu com o mesmo padrão.

No grupo P90(NTC), que utilizou o sistema adesivo P90, houve formação de tags no interior dos túbulos dentinários, também foi observado a presença de fendas na interface. Após envelhecimento, observou-se fenda na interface e ausência de tags. 



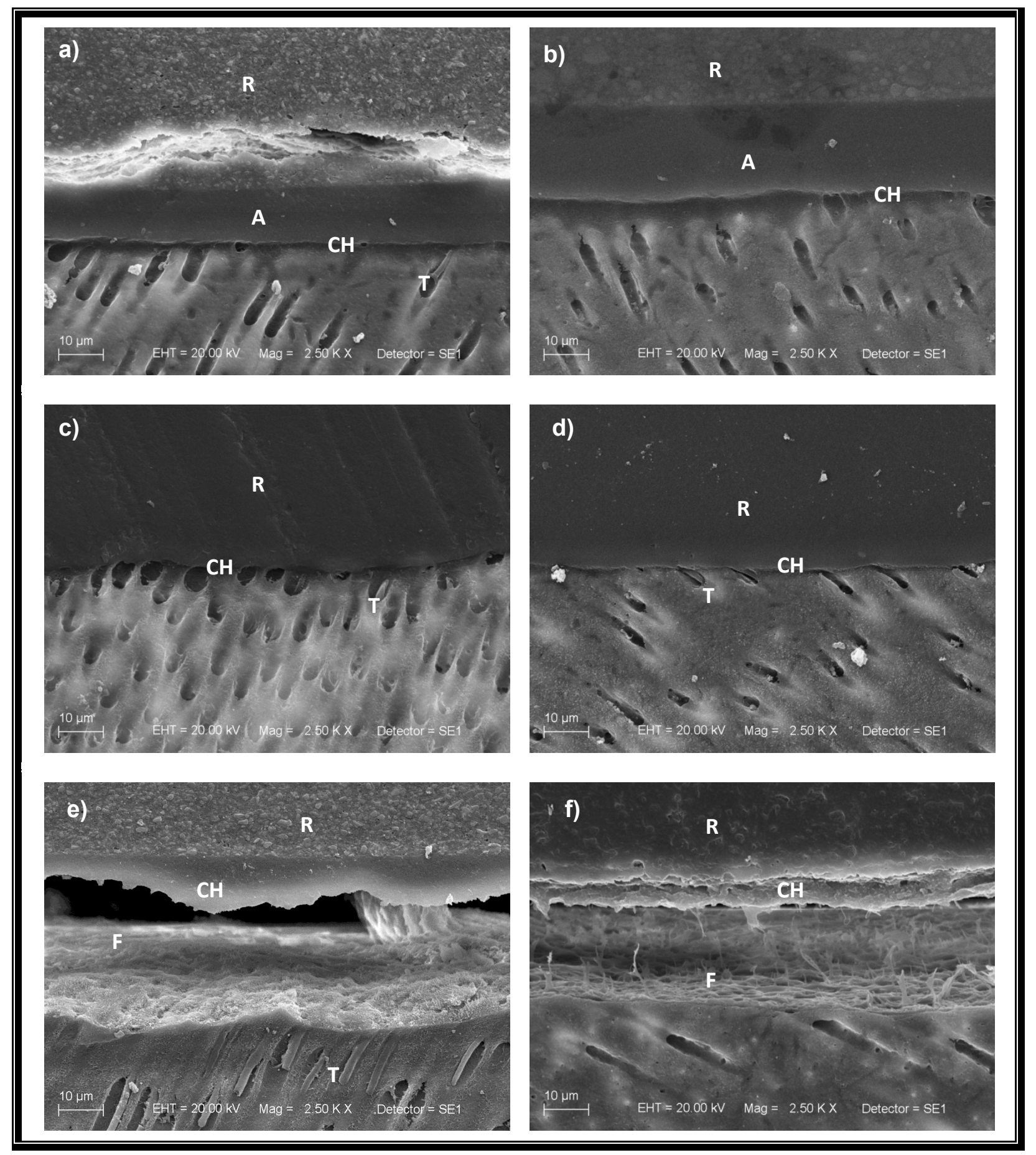

Figura 8. Imagens representativas da interface adesiva de cada grupo estudado, sendo: a) Z250(NTC); b) Z250(TC); C) K (NTC); K (TC); P90 (NTC); P90(TC).

R=Resina; CH: Camada Híbrida; F: Fenda na interface; T: Tags. 

Discussão 



\section{DISCUSSÃo}

Novas resinas estão sendo desenvolvidas com novas composições, dentre elas as que são consideradas de baixa contração de polimerização. A finalidade maior destas é a redução do estresse gerado na interface adesiva logo após a fotoativação visando prolongar a vida útil clínica das restaurações dentárias. O conhecimento dos valores de adesão destes materiais ao substrato dentário é de fundamental importância. Assim, neste estudo foi avaliada à resistência à microtração de compósitos com diferentes composições químicas como Kalore, P90 e Z250. Assim, as médias de resistência encontradas 24 horas após a realização das restaurações foram: para o grupo $Z 250=25.29 \mathrm{MPa}, K=9,69 \mathrm{MPa}$ e $\mathrm{P} 90=9,81 \mathrm{MPa}$.

Em relação à metodologia utilizada inicialmente, foi realizada a indução de cárie artificial previamente aos preparos cavitários, onde optou-se pelo modelo proposto por Manesh et al., 2009, por ser uma técnica eficiente e simples. A remoção da dentina desmineralizada foi realizada com broca de aço em baixa rotação, e o protocolo de desmineralização foi realizado para que o preparo cavitário e as restaurações não fossem realizadas em dentina sadia. Após a remoção da dentina desmineralizada utilizou-se sistemas adesivos autocondicionantes que são classificados de acordo com a estratégia adesiva utilizada e números de passos envolvidos na aplicação (Van Meerbeek et al., 2011).

Neste estudo, foi utilizada a resina P90 com sistema adesivo autocondicionante próprio. Assim, optou-se pelo sistema adesivo Clearfil SE Bond para ser utilizado previamente às resinas Kalore e Z250 que não possuem sistema adesivo próprio. O Clearfil SE Bond é considerado padrão ouro, possui técnica simplificada, é clinicamente estável e apresenta boa resistência mecânica (Kameyamana et al., 2009, Pneumans et al., 2010). Esse sistema adesivo possui pH próximo de 2 , sendo considerado como "leve" em relação a sua agressividade e isso favorece a presença de cristais de hidroxiapatita em torno de fibras colágenas, justificando seu bom desempenho (Yoshida et al., 2004). O sistema adesivo P90 é também considerado como "leve" na sua agressividade, pois possui pH 2,7 (Sarr et al., 2010). 
O teste de microtração, utilizado neste estudo, demonstrou que os valores de resistência adesiva foram maiores nos grupos que utilizaram o sistema adesivo Clearfil SE Bond associado às resinas Z250 e Kalore. De acordo com estudo realizado por Feitosa et al., 2012, cujos materiais apresentavam diferença na adesão entre os sistemas adesivos, no qual o Clearfil SE Bond apresentou maiores valores de resistência adesiva tanto para o grupo 24 horas como para o grupo após envelhecimento. Neste mesmo estudo, foi utilizado um menor número de ciclos 5.000 TC (termociclagem) e já foi possível encontrar resultados desfavoráveis em relação ao sistema silorano, o que concorda com os resultados deste estudo. Giacobbi \& Vamdewalle., 2012, comparando os sistemas adesivos Filtek Silorano e Clearfil SE Bond constataram que após os períodos de envelhecimento houve redução nos valores de microtração dos dois sistemas comparados, no entanto não houve diferença estatística quando as resinas foram comparadas. Van Ende et al., 2012, realizaram um estudo onde avaliaram a resistência adesiva após uma semana de armazenamento em água das resinas, silorano com seus sistema adesivo próprio e uma resina convencional Z100 com um sistema adesivo de dois passos, e obtiveram maior força de adesão para resina Z100 quando comparada a resina silorano. Os autores também avaliaram a resina Kalore, comparando com outra resina de baixa contração de polimerização e com a resina convencional Z100 associadas com adesivo de um único passo, e obtiveram maior resistência adesiva para as resinas de baixa contração de polimerização. Os autores afirmam que o adesivo de um passo é mais sensível ao estresse de contração de polimerização do que $o$ adesivo de dois passos.

Neste estudo, a técnica de inserção das resinas compostas por incrementos foi realizada pelo mesmo operador e sempre da mesma forma, o que provavelmente não interferiu no processo de adesão. Van Ende et al., 2010, observaram que quando a inserção foi feita em único incremento, independentemente do tipo de resina utilizada, houve diminuição nos valores de resistência adesiva, sugerindo que a técnica incremental deve ser utilizada para todos os tipos de resinas. Almeida et al., 2011, realizaram um estudo no qual avaliaram a resistência adesiva pela microtração das resinas Filtek Silorano e Z250 com duas técnicas de inserção para cada resina, sendo a técnica incremental e única inserção em cavidades Classe I. 
Após 24 horas de armazenamento realizaram os testes e observaram maiores valores de resistência adesiva nos grupos da técnica incremental e, comparando os resultados entre as resinas, a resina Z250 apresentou valores maiores de resistência adesiva do que a resina Silorano, o que está de acordo com nosso estudo.

Uma possível justificativa para falha de adesão da resina a base de Silorano P90 pode estar relacionada à sua alta viscosidade, o que resulta em pequena molhabilidade do substrato, sendo que sua manipulação é mais difícil. Segundo alguns autores (Yamazaki et al., 2006, Van Ende et al., 2010 e Van Ende et al., 2012), os materiais de baixa contração de polimerização apresentam falhas na adaptação por apresentaram alta viscosidade, o que dificulta a adaptação dos mesmos, e favorecendo a formação de bolhas no interior das restaurações.

Para simular as alterações térmicas que ocorrem na boca, foi utilizado o envelhecimento das restaurações no qual os corpos de prova foram submetidos a alterações térmicas (do Amaral et al., 2007 e Feitosa et al., 2010). Neste estudo, foram realizados 12.000 ciclos de termociclagem, simulando envelhecimento por 6 meses do material na cavidade bucal. Isso justifica a diminuição dos valores de resistência em todos os grupos, pois as médias encontradas após o envelhecimento por termociclagem foram menores que os valores iniciais. Grupo $Z 250(T C)=13,00$ $\mathrm{MPa}, \mathrm{K}(\mathrm{TC})=4.30 \mathrm{MPa}$ e $\mathrm{P} 90(\mathrm{TC})=0 \mathrm{MPa}$. Esta redução está de acordo com a literatura, pois, Krajagta \& Srrisawasdi 2011, mesmo realizando um tempo de envelhecimento menor ( 3 meses), encontraram resultados semelhantes aos deste estudo. Por outro lado, Sampaio et al., 2013 realizaram um estudo com 4 tipos de sistemas adesivos, sendo que 2 tipos de sistemas adesivos foram os mesmos utilizados no presente estudo (sistema adesivo P90 e o Clearfil SE Bond, associados à resina P90 e à resina convencional $\mathrm{Z350}$ ) e não encontraram diferença estatística na adesão dos materiais metacrilato e Silorano, e nem para o fator tempo (24 horas/ 6 meses), o que difere do nosso estudo. 0 baixo valor de resistência do grupo da P90 pode ser explicado devido ao aparecimento de bolhas pelo acúmulo de água na interface adesiva, pois o sistema adesivo P90 possui características hidrófobas, com elevada concentração de íons, como o HEMA (2-hidroxietil metacrilato), que induzem a movimentação da água da dentina para a interface da camada híbrida, e com isso, acumulam-se e induzem o aparecimento de bolhas que comprometem a 
união entre o primer e o adesivo, causando muitas falhas na união dentina/ restauração (Van Ende et al., 2010; Van Meerbeek et al., 2011).

A análise das fraturas demonstrou predominância de fratura mista para todos os grupos. Estas fraturas indicam que a força realizada para remover a resina do corpo de prova foi exercida exatamente na interface, sendo assim os valores alcançados são mais fidedignos.

Em relação à interface pôde-se observar que quando o adesivo self etching da P90 associada à resina P90 tanto às 24 horas como após envelhecimento estavam presentes gaps interfaciais, que podem justificar os baixos valores de resistência à microtração. Nos demais grupos foram observados camadas do sistema adesivo, Clearfill SE Bond, espessa densa e presença de tags no interior dos túbulos dentinários. 
Conclusão 



\section{CONCLUSÃo}

Baseado nos resultados obtidos neste estudo, e dentro das limitações de um estudo in vitro, é lícito concluir que:

- As resinas de baixa contração de polimerização apresentam os menores valores médios de resistência à microtração tanto às 24 horas quanto após procedimentos de envelhecimento da interface adesiva.

- A análise do padrão de fratura por meio de MEV após o teste de microtração demonstrou que fraturas mistas foram prevalentes nos grupos Z250(NTC), Z250(TC), K(NTC), K(TC), P90(NTC). E fratura adesiva foi prevalente no grupo $\mathrm{P} 90(\mathrm{TC})$.

- Em relação a interface adesiva, quando o sistema adesivo Clearfill SE Bond foi utilizado, pôde-se observar uma camada de adesivo espessa, camada híbrida e tags. No entanto, para o sistema adesivo P90, não foi possível observar camada híbrida, tags e foram observadas fendas interfaciais tanto às 24 horas como após envelhecimento. 



\section{Referência Bibliográficas}





\section{REFERÊNCIAS BIBLIOGRÁFICAS}

Almeida e Silva JS, Rolla JN, Baratieri LN, Monteiro S Jr. The influence of different placement techniques on the microtensile Bond strength of low- shrink silorane composite bonded to Class I cavites. Gen Dent 2011;59(6):233-7.

Amaral FL, Colucci V, Souza-Gabriel AE, Chinelatti MA, Palma-Dibb RG, Corona SA. Bond durability in erbium:yttrium-aluminum-garnet laser-irradiated enamel. Lasers in Medical Science. 2010;25(2):155-163.

Amaral FL, Colucci V, Palma- Dibb RG, Corona SA. Assessment of in vitro methods used to promote adhesive interface degradation: a critical review. J Esthet Restor Dent 2007; 19(6):340-54.

Baracco B, Perdigão J, Cabrera E, Giráldez I, Ceballos L. Clinical evaluation of a lowshrinkage composite in posterior restorations: one-year results. Oper Dent 2012;37(2):117-129.

Bedran de Castro AKB, Pereira PN \& Pimenta LAF. Long-term bond strength of restorations subjected to thermalmechanical stresses over time. American Journal of Dentistry 2004;17(5):337-341.

Boaro LC, Gonc,alves F, Guimarães TC, Ferracane JL, Versluis A, Braga RR. Polymerization stress, shrinkage and elastic modulus of current low-shrinkage restorative composites. Dental Materials. 2010;26(12): 1144-1150.

Boullaguet S, Gamba J, Forchelet I, Wataha JC. Dynamics of composite polymerization mediates the development os cuspal strain. Dent Mater 2006;22(10) 989-902. 
Carrilho MRO, Carvalho RM, Tay FR \& Pashley DH (2004) Effects of storage media on mechanical properties of adhesive systems. American Journal of Dentistry 2004;17(2):104-108.

De Munck J, Van Meerbeek B, Yoshida Y, Inoue S, Vargas M, Suzuki K, et al. Four year water degradation of total - etch adhesives bonded to dentin. Journal of Dental Research 2003;82(2):136-140.

Dopheide B, Heiss M, Lee R, Reinfields K. Kalore technical manual. GC Co. 2010.

do Amaral FL, Colucci V, de Souza-Gabriel AE, Chinelatti MA, Palma-Dibb RG \& Corona AS. Adhesion to Er:YAG laser-prepared dentin after long-term water storage and thermocycling. Operative Dentistry 2008;33(1):51-58.

Eick JD, Smith RE, Pinzino CS, Kostoryz EL. Stability of silorane dental monomers in aqueous systems. J Dent. 2006;34(6):405-410.

El-Kalla IH, García-Godoy F. Bond strength and interfacial micromorphology of four adhesive systems in primary and permanent molars. Asdc J Dent Child 1998;65(3):169-76.

Ermis RB, De Munck J, Cardoso MV, Coutinho E, Van Landuyt KL, Poitevin A, Lambrechts P, Van Meerbeek B. Bond strength of self-etch adhesives to dentin prepared with three different diamond burs. Dent Mater 2008;24:978-85.

Ernst CP, Meyer GR, Klöcker K, Willershausen B. Determination of polymerization shrinkage stress by means of a photoelastic investigation. Dent Mater 2004;20(4):313-321.

Feilzer AJ, De Gee AJ, Davidson CL. Quantitative determination of stress reduction by flow in composite restorations.Dental Materials 1990;6:167-71. 
Feilzer AJ, de Gee AJ, Davidson CL. Setting stresses in composites for two different curing modes. Dental Materials 1993;9:2-5.

Feitosa VP, Medina AD, Puppin-Rontani RM, Correr- Sobrinho L, Sinhoreti MA.Effect of resin coat technique on bond strength of indirect restorations after ther mal and load cycling. Bull Tokyo Dent Coll 2010;51(3):111-8.

Fukushima $\mathrm{T}$, Inoue $\mathrm{Y}$, Miyazaki $\mathrm{K}$, Itoh $\mathrm{T}$. Effect of primers containing $\mathrm{N}$ methylolacrylamide or $\mathrm{N}$-methylolmethacrylamide on dentin bond durability of a resin composite after 5 years. Journal of Dentistry 2001;29(3):227-234.

Giacobbi MF, Vandewalle KS. .Microtensile bond strength of a new silorane-based composite resin adhesive. Gen Dent 2012;60(3):148-52.

Gonzalez-Lopez S, Vilchez Dı'az MA, de Haro-Gasquet F, Ceballos L, de Haro-Munoz C. Cuspal flexure of teeth with composite restorations subjected to occlusal loading. The Journal of Adhesive Dentistry 2007;9(1); 11-15.

Kameyama A, Aizawa K, Kato J, Hirai Y. Tensile Bond strength of single- step selfetch adhesives to Er: YAG laser irradiated dentin. Photomed Laser Surg 2009; 27(1):3-10.

Krajangta N, Srisawasdi S. Microtensile bond strength of silorane-based resin composite and its corresponding adhesive in Class I occlusal restorations. Am J Dent $2011 ; 24(6): 346-53$.

Ilie $\mathrm{N}$, Jelen $\mathrm{E}$, Clementino-Luedemann T, Hickel R. Low-shrinkage composite for dental application. Dent Mater J 2007;26(2):149-155.

Manesh SK, Darling CL, Fried D. Nondestructive assessment of dentin demineralization using polarization-sensitive optical coherence tomography after 
exposure to fluoride and laser irradiation. J Biomed Mater Res B Appl Biomater 2009;90(2):802-812.

Nakabayashi N, Pashley DH. Hibridization of dental hard tissues. Tokio: Quintessence Publishing, 2000.

Nakabayashi N, Saimi Y. Bonding to intact dentin. J Dent Res 1996;75(9):1706-1715.

Naoum SJ, Ellakwa A, Morgan L, White K, Martin FE, Lee IB. Polymerization profile analysis of resin composite dental restorative materials in real time. J Dent 2012;40(1):64-70.

Pashley DH, Sano H, Ciucchi B, Yoshiyama M, Carvalho RM. Adhesion testing of dentin bonding agents: a review. Dent Mater 1995,11(2):117-25.

Peumans M, Kanumilli P, De Munck J, Van Landuyt KL, Poitevin A, Lambrechts P, Meerbeek B. Clinical effectiveness of comtemporary adhesives: a systematic review of current clinical trials. Dent Mater 2005,26(12):1176-84.

Peutzfeldt A. Resin composites in dentistry the monomer systems. Eur J. Oral Sci 1997;105(2):97-116.

Saar M, Kane AW, Vreven J, Mine A, Van Landuyt KL, Pneumans M, Lambrechts P, Van Meerbeek B, de Munck J. Microtensile bond strength and interfacial characterization of 11 contemporary adhesives bonded to bur-cut dentin. Oper Dent 2010;35(1):94-104.

Sano H, Shono T, Sonoda H, Takatsu T, Ciucchi B, Carvalho R, Pashley DH. Relationship Between surface área for adhesion and tensile Bond strengthEvaluation of a microtensile Bond test. Dent Mater 1994;10(4):326-40. 
Sampaio RK, Wang L, Carvalho RV, Garcia EL, Andrade AM, Klein- Júnior CA, Grande $\mathrm{RH}$, Moura SK. Six-month evaluation of a resin/dentin interface created by methacrylate and silorane-based materials. J Appl Oral Sci 2013;21(1):80-4.

Santini A, Miletic V. Comparison of the hybrid layer formed by silorane adhesive, onestep self-etch and etch and rinse systems using confocal micro-Raman spectroscopy and SEM. J Dent 2008;36:683-91.

Scherrer SS, Cesar PF, Swain MV. Direct comparison of the bond strength results of the different test methods: a critical literature review. Dent Mater 2010; 26(2):78-93.

Senawongse P, Haranirattisai C, Shimada Y, Tagami J. Effective Bond strength of current adhesive systems on deciduous and permanent dentin. Operat Dent 2004;29(2):196-202.

Shono Y, Terashita M, Shimada J, Kozono Y, Carvalho RM, Russell CM, Pashley DH. Durability of resin-dentin bonds. Journal Adhesive Dentistry 1999;1(3):211-218.

Takahashi H, Finger WJ, Wegner K, Utterodt A, Komatsu M, Wöstmann B, Balkenhol $M$. Factors influencing marginal cavity adaptation of nanofiller containing resin composite restorations. Dent Mater. 2010; 26(12):1166-1175.

Van Ende A, De Munk J, Mine A, Lambrechts P, Van Meerbeek B. Does a lowshirinking composite induce less stress at the adhesive interface? Dent Mater 2010;26(3):215-22.

Van Ende A, Mine A, De Munk J, Van Meerbeek B, Poitevin A. Bonding of lowshrinking composites in high C-factor cavities. J. Dent 2012 40(4):295-303.

Van Meerbeek B, Yoshihara K, Yoshida Y, Mine A, De Munk J, Van Landuyt KL. State of tha art of self- etch adhesives. Dent Mater 2011;27(1):17-28. 
Wei YJ, Silikas N, Zhang ZT, Watts DC. Hygroscopic dimensional changes of selfadhering and new resin-matrix composites during water sorption/desorption cycles. Dent Mater 2011;27(3):259-266.

Wei YJ, Silikas N, Zhang ZT, Watts DC. Diffusion and concurrent solubility of selfadhering and new resin-matrix composites during water sorption/desorption cycles. Dent Mater. 2011; 27(2):197-205.

Weinmann W, Thalacker C Guggenberger R. Siloranes in dental composites. Dent Mater. 2005;21(1):68-74.

Yamazaki PC, Bedran- Rulso AK, Pereira PN, Wsift EJ. Microleakage evaluation of a new low- shrinkage composite restorative material. Oper Dent 2006;31(6)670-6.

Yoshida Y, Nagakane K, Fukuda R, Nakayama Y, Okazaki M, Shintani H, Inoue S, Tagawa Y, Suzuki K, De Munk J, Van Meerbeek B. Comparative study on adhesive performance of functional monomers. J Dent Res 2004;83(6):454-8. 
Anexo 



\section{FACULDADE DE \\ ODONTOLOGIA DE RIBEIRÃO \\ PRETO/ FORP/ USP}

\section{PARECER CONSUBSTANCIADO DO CEP}

\section{DADOS DO PROJETO DE PESQUISA}

Título da Pesquisa: AVALIAÇÃo IN VITRO DA MICROTRAÇÃO DE RESINAS DE BAIXA CONTRAÇÃO DE POLIMERIZAÇÃO EM DENTINA: INFLUÊNCIA DA DEGRADAÇÃO DA INTERFACE ADESIVA

Pesquisador: Bárbara Jarreta

Área Temática:

Versão: 2

CAAE: 09199913.3 .0000 .5419

Instituição Proponente: Universidade de Sao Paulo

Patrocinador Principal: Financiamento Próprio

\section{DADOS DO PARECER}

Número do Parecer: 283.612

Data da Relatoria: 16/05/2013

\section{Apresentação do Projeto:}

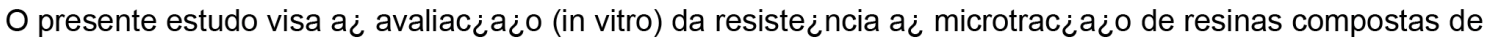

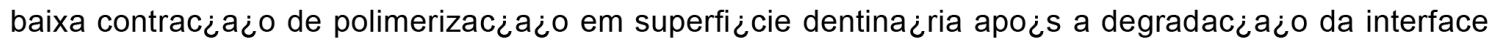
adesiva. Sera ¿o utilizados 60 molares humanos que tera $\_$a superfi ¿cie oclusal seccionada para

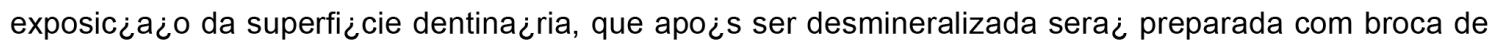

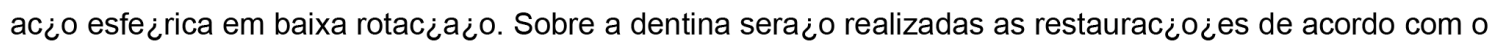
sistema restaurador : GI ¿ Sistema Adesivo Clearfil SE Bond + Resina Filtek Z250 (Controle), GII - Sistema Adesivo Clearfil SE Bond + Resina Kalore e GIII Sistema Adesivo P90 + Resina Filtek P90. Apo ¿s os procedimentos restauradores, cada grupo sera $\_$dividido em 2 subgrupos, de acordo com o tempo de termociclagem e armazenamento em aigua: A - Sem TC/ 24 h de armazenamento em aigua; B 12.000TC/ 6 meses de armazenamento em a¿gua. Em seguida, os dentes sera ¿o cortados para a

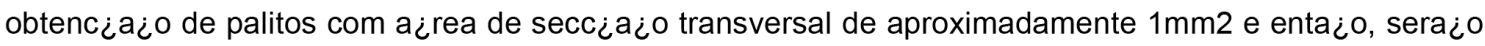
realizados os testes de microtrac $\_a \_o$.

\section{Objetivo da Pesquisa:}

O objetivo deste projeto $e_{\iota}$ analisar a resiste $\_n c i a$ adesiva dos diferentes materiais, por meio de microscopia eletro ¿nica de varredura.

Endereço: Avenida do Café $\mathrm{s} / \mathrm{n}^{\circ}$

Bairro: Monte Alegre CEP: 14.040-904

UF: SP Município: RIBEIRAO PRETO

Telefone: (16)3602-0251 Fax: (16)3602-4102 E-mail: cep@forp.usp.br 


\section{FACULDADE DE ODONTOLOGIA DE RIBEIRÃO PRETO/ FORP/ USP}

Continuação do Parecer: 283.612

Avaliação dos Riscos e Benefícios:

O estudo na ¿o apresenta Riscos. Em relac ¿a¿o aos Benefi ¿cios, busca-se a realizac ¿a ¿o de procedimentos restauradores menos invasivos, possibilitando a preservac $\_a_{i} \circ$ do tecido denta $\_$rio sadio, aumentando assim as restaurac $¿$ ¿ $¿$ es em resina compostas em dentes posteriores. deste modo, pretende-

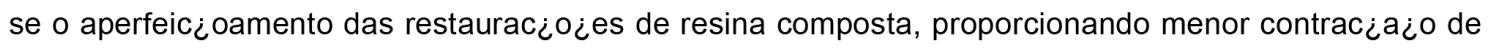

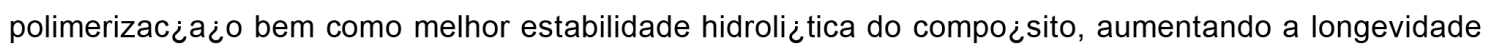
dessas restaurac ¿o¿es.

Comentários e Considerações sobre a Pesquisa:

A pesquisa e $i$ relevante e bem embasada na literatura.

Considerações sobre os Termos de apresentação obrigatória:

Adequados.

Recomendações:

Nada a relatar

Conclusões ou Pendências e Lista de Inadequações:

Pendências atendidas.

Situação do Parecer:

Aprovado

Necessita Apreciação da CONEP:

Não

Considerações Finais a critério do CEP:

conforme deliberado na $148^{a}$ reunião realizada em 16/05/2013

RIBEIRAO PRETO, 24 de Maio de 2013

Assinador por:
JOSÉ TARCíSIO LIMA FERREIRA

(Coordenador)

Endereço: Avenida do Café $s / n^{\circ}$

Bairro: Monte Alegre

UF: SP

Município: RIBEIRAO PRETO

Telefone: (16)3602-0251

Fax: (16)3602-4102

CEP: $14.040-904$ 